\title{
Francisco José de Caldas y las transformaciones en la visión del paisaje geográfico en Colombia
}

\author{
Francisco José de Caldas and the transformations \\ in the vision of the geographical landscape in Colombia
}

\author{
Andrés Fernando Castiblanco Roldán*
}

Fecha de recibido: 13 de noviembre de 2019

Fecha de aceptado: 5 de junio de 2020

\section{Resumen}

El paisaje ha servido en los estudios geográficos como unidad de análisis territorial a través de elementos brindados por la Geografía cultural para integrar las geomorfologías del mundo físico y las morfologías culturales desarrolladas por el ingenio humano. El presente artículo es un resultado del proyecto de investigación: Marcas Territoriales y Paisaje, el cual apuesta por caracterizar el análisis de los territorios y sus comunidades en función de los conflictos con las transformaciones del modelo de producción global en Latinoamérica a través de una apuesta metodológica trayectiva nutrida por autores claves como: A. Berque (2009), Cosgrove (2008) y Nogue (2010). Como resultado se presenta una aproximación genealógica de la visión paisajística en Colombia que posiciona desde una perspectiva geográfica poco visitada el papel de Francisco José de Caldas como pensador bisagra en la transformación de las visiones del paisaje colonial al paisaje republicano en Colombia y quizá en Latinoamérica.

Palabras clave: paisaje, Mundo Colonial, cronistas, viajeros y territorios.

\section{Abstract}

The landscape has served in geographical studies as a unit of territorial analysis through elements provided by cultural geography to integrate the

* Universidad Distrital Francisco José de Caldas, Colombia, correo electrónico:

afcastiblancor@udistrital.edu.co 
geomorphologies of the physical world and the cultural morphologies developed by human ingenuity. This article is a result of the research project: Territorial Marks and Landscape, which is committed to characterize the analysis of territories and their communities based on conflicts with the transformations of the global production model in Latin America through a methodological commitment trajectory nurtured by key authors such as: A. Berque (2009), Cosgrove (2008) and Nogue (2010). As a result, a genealogical approach to the landscape vision in Colombia is presented, which positions Francisco José de Caldas's role as a hinge thinker in the transformation of visions of the colonial landscape to the republican landscape in Colombia and perhaps in Latin America from a little-visited geographical perspective.

Key words: landscape, Colonial World, chroniclers, travelers and territories.

\section{Apuntes de pensamiento geográfico y paisaje}

En principio, el paisaje a pesar de no ser denominado como tal sino hasta la modernidad (Maderuelo, 2006), se constituyó como forma principal de reconocimiento del territorio. Cuando se revisan los textos de viajeros y científicos, incluso si se partiera antes de la era cristiana desde los viajes de Heródoto de Halicarnaso transcritos en su Logoi, podría decirse que el paisaje como unidad de percepción del mundo se configuró en un recurso retórico de primera mano para leer el espacio y por lo tanto se instituye como técnica de descripción de los lugares, las morfologías y las gentes.

En su primera investigación (Lacarrieré, 1973) sobre "los bordes de la tierra", Heródoto propone una ecúmene y una anecúmene, para dar cuenta de la tierra poblada y la ignota o sin habitar, a través de sus itinerarios de batallas, sitios y reinos, la descripción de los pueblos, sus mitos y sus lugares configuran la noción del paisaje como instrumento de encuentro con el territorio. No obstante, las nociones espaciales del arte plástico en el Renacimiento (Maderuelo, 2006; Cosgrove, 2008) y las expediciones de reconocimiento, inventario nacionalsoberano de las nacientes naciones modernas en los siglos XVIII y XIX se valen del paisaje para medir y cuantificar las posesiones y gentes de las regiones en estos escenarios donde las disciplinas entre ellas la Geografía encuentra su nicho, pensadores como Humboldt, Ritter y en adelante una serie de viajeros y científicos hijos del iluminismo y posteriormente del romanticismo, consolidarían sobre el paisaje una noción que derivó en su interpretación en direcciones independientes como la artística, o la arquitectónica entre otras ramificaciones que fragmentaron una integralidad dialógica entre estéticas, técnicas y territorios. 
Más tarde en el inicio del siglo Xx, Carl Sauer en 1925 propone la importancia del estudio del paisaje para comprender el sentido de una Geografía cultural y sus confines tanto disciplinares como epistemológicos, para este geógrafo norteamericano:

[...] el lugar de una ciencia que encuentra su campo entero en el paisaje, sobre la base de la realidad significante de relación corológica. Los fenómenos que constituyen no son simplemente clasificados, sino que están asociados, o son interdependientes. Descubrir esta "conexión de los fenómenos y su orden" real es una tarea científica, la única a la cual - de acuerdo a nuestra posición - debería dedicar sus energías la geografía (Sauer, 2006).

Para Sauer, el paisaje es una generalización derivada de la observación de escenarios individuales (Sauer, 2006) en la cual cada investigador define de acuerdo a unas variables que pretende analizar la visión sobre el mismo. Esta visión de preminencia perceptual enriquecería sus potencialidades a fines del mismo siglo que podría situarse como una disminución de la incertidumbre de la Guerra fría y por lo tanto la posibilidad de un intercambio sobre los estudios del territorio desde la geografía y su apertura a otras disciplinas de las ciencias sociales, tan recordada por las nociones del sistema mundo de Wallerstein a mediados de la década de los ochenta con su Abrir las Ciencias Sociales (1996), que propondrían enfoques y acercamientos en función de comprender las dinámicas espaciales en sus diferentes escalas como estrategia de resistencia y de construir sistemas de pensamiento espacial renovadores para un mundo de posguerra que como lo señaló en su momento Yves Lacoste (1976) eran formas del pensamiento que mostraban a la Geografía como una disciplina de control territorial para los instrumentos de poder de los estados pero a su vez manipulable políticamente para la conciencia de los ciudadanos.

En este contexto de excitación intelectual por el papel del espacio frente al tiempo y como ruptura de muchas de las lógicas del neopositivismo fortaleció el papel de la Geografía humana en tanto que los estudios sobre el paisaje siguieron enfocados en la asociación: selección-percepción, dinamismo que viene a completarse como triada con el aporte de Denis Cosgrove (2008), cuando alude a una definición desde la experiencia de quienes referencian o sitúan su percepción, la cual es atravesada, por el lugar que ocupan en la producción de tales espacios. Una evidencia de estos enfoques es la lectura del Paisaje como emergencia en el arte renacentista, propio de las burguesías italianas desde el modelo de las Ciudades-Estado y su relación con el territorio (Cosgrove, 2008).

Una triada en principio subjetivo-sensorial, posiciona al intérprete como lector territorial, en ella se ubica la sensibilidad como forma de lectura/sentida del paisaje entre la selección-la forma y la experiencia, Figura 1. 


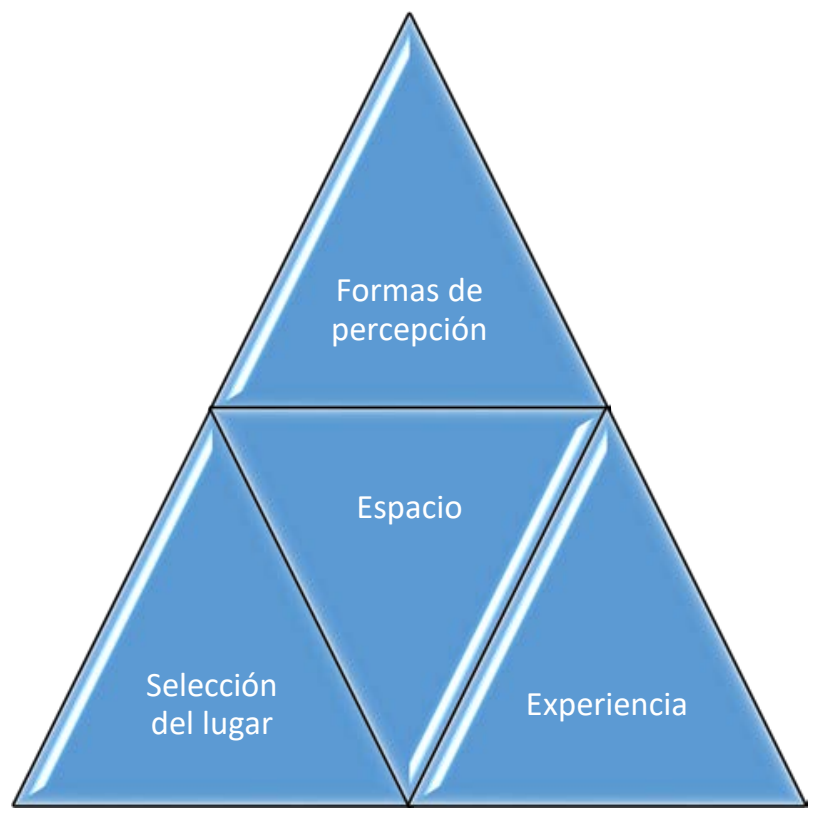

Figura 1. Triada subjetivo-sensorial de análisis del paisaje.

Fuente: elaboración propia.

Tales enfoques trazan sus epistemes del paisaje de Norteamérica a Europa. En el caso de la academia francesa, se posicionan vertientes que establecen la percepción desde un materialismo dialéctico que se divide entre las nociones del paisaje construido como objeto estético y dinamizador de las identidades y las comunidades (Cosgrove, 2008; Nogué, 2010) y del pensamiento paisajero y las relaciones con lo originario y lo sagrado (Berque, 1990; 2009) y lo experiencial de lo colectivo en Norteamérica (Tuan, 2009). En la visión de corte mesológico francés se plantea un cisma estético espacial de los pueblos paisajeros y los pueblos sin paisaje, pero explotadores del mismo. Un debate que Augustin Berque sitúa en consideración a la hegemonía del Pensamiento Occidental Moderno Clásico (POMC), frente al orientalismo entre otras manifestaciones no coloniales de la apropiación social del espacio.

Agustín Berque (1990) pone de relieve la existencia de un conjunto de sentimientos, imaginaciones o dinámicas que configuran la energética del espacio. En su examen del Fudosei japonés, propone la fluctuación natural a través de la medianza, donde plantea la mirada al espacio como el conjunto de dinámicas que van de la naturaleza al hombre y del hombre hacia la naturaleza. Una serie de órdenes y relaciones que se hallan en desequilibrio en ocasiones pero que 
desembocan en la definición clara de un escenario urbano. De allí que es posible aludir a la relación directa que teje la experiencia con el espacio como evolución en la ciudad como mediación, en este caso sensorialmente perceptible en el paisaje.

Para Berque, la invención del paisaje tiene que ver con la relación que se establece entre la humanidad y la naturaleza en una convergencia del Mundo Ambiente que lleva la cosmofanía como forma de percepción del mudo propio (Berque, 2014) estas formas dialogan con las mutaciones en el lenguaje de las técnicas de relación con el territorio.

Por ejemplo, el mismo concepto de paisaje, como se dijo anteriormente, ve su origen en el marco de la modernidad renacentista, en las tecnologías del lenguaje en expresiones como el Landschaft alemán o el Landscape inglés que remiten a la región, a la tierra (Maderuelo, 2006) que se concibe como forma sensorial a lo humano, para el caso de la raíz latina que sería el énfasis para el español, remite al Pagus latino que referencia la aldea, en la tierra, la integración de lo humano a lo natural en un vocablo que da origen a la expresión Pago como conjunto de lo rural, el cual mutaría a la ideología de la región en país y en la visión de los elementos (artificiales y naturales) en conjunto en el paisano en últimas el actante del paisaje.

El paisaje se presenta como expresión de la relación entre la forma y la función, entre las figuras que se perciben y se aglomeran a primera vista, pero que encarnan otro tipo de circulaciones, de flujos y que en su devenir son oscilantes, latentes, siempre dinámicas, son las contracciones que el medio deja abundar o suprime en la coacción de lo natural y lo diseñado, entre la amalgama terrestre y por lo tanto, hija de los elementos y las fluctuaciones humanas provistas de encantos y desencantos, ensueños y tejidos cargados por bazas de historia social.

En el plano latinoamericano, con respecto al tema se visibilizan algunos programas de trabajo sobre las dinámicas del espacio habitado como las de Milton Santos cuyo producto Por una Geografía nueva de 1979, desemboca en una serie de trabajos que van con la Metamorfosis del espacio habitado (1996), pasando por La naturaleza del espacio (2000), hasta Por otra globalización (2001) al analizar el marco de una Geografía humana que en sus perspectivas desplegó en sus hallazgos y reflexiones el papel del paisaje.

Para Santos el punto de partida se ubica en "[...] el dominio de lo visible, lo que la vista abarca" (Santos, 1996: 59) para consolidar desde una postura materialista de la producción social del espacio, una serie de ejemplos en los cuales hacen juego la artificialidad de la técnica humana y sus modos de subsistencia frente a la naturaleza.

Una visión que dialoga con la triada anterior al estar ubicado en el campo de la relación selección-percepción. En Colombia en la misma época de transiciones territoriales y jurídicas con la constitución de 1991, se elaboraron estudios y análisis de los elementos del paisaje, se sugieren sus organizaciones y una serie de aplicaciones que involucran lo cultural, lo económico y lo sociológico como ejes de 
diálogo con el saber geográfico, en este sentido los estudios sobre el paisaje como herramienta u objeto van de grupos de estudio organizados en torno al tema (Cortes, Rincón y Sarmiento, 1998; Peña, Gómez y Riveros, 1998) a análisis que involucran su papel y su interpretación en contextos de problemas culturalesterritoriales (Molano, 1995; Rozo, 2010; Orozco y Salcedo, 2011; Giraldo, 2019) y, finalmente, apuestas colectivas que buscan posicionar el lugar del Paisaje como campo de trabajo en las disciplinas tanto geográficas como ambientales (Barrera y Monroy, 2014).

En Colombia como en otros escenarios latinoamericanos, desde el informe o relación de mando virreinal pasando por los diarios de viaje, o de las crónicas hasta el artículo de corte crítico publicado en el periódico matutino y otros repertorios íntimos, se involucran una serie de aspectos que se pueden analizar a partir del contexto del observador/creador y lo qué describe y busca con su relato. En este sentido, se realiza una trayección de los paisajes con algunos autores, narraciones y documentos, en un recorrido sobre estas visiones para llegar al aporte directo realizado por Francisco José de Caldas como científico, al tiempo que como personaje político de la revolución de Independencia colombiana de la que fue pionero junto a su maestro José Celestino Mutis, de una valoración sensible del mundo natural a partir de las descripciones y estudios de los paisajes andinos. Estos informes publicados en la mayoría en su semanario, entre otras publicaciones, contribuyeron a la construcción de un imaginario paisajístico con el cual se desarrolló buena parte de la historia de la cultura colombiana como su geografía.

Para poder abordar tal concepto, es necesario mencionar que Fernand Braudel (1989) aunque no alude de forma directa a la noción como tal, construye desde su método histórico una visión reconstructiva que recoge en una apuesta total los elementos biofísicos y humanos de los escenarios. En su texto El Mediterráneo basta con echar un vistazo al primer párrafo que muestra esa forma de ver:

En este libro, los barcos navegan; las olas repiten su canción; los viñadores descienden por las colinas repiten su canción; los viñadores descienden por las colinas de Cinque Terre, en la rivera genovesa; se varean los olivos en Provenza y en Grecia; los pescadores arrojan sus redes sobre la laguna inmóvil de Venecia o en los canales de Djerba; los carpinteros construyen barcas parecidas a las de ayer... Y una vez más, al contemplarlos, nos salimos del tiempo (p. 9).

De tal manera que el presente artículo presenta una dimensión desde la geografía histórica de la posibilidad de desarrollar en términos de una trayección (Berque, 2009), una aproximación a la genealogía del paisaje en Colombia a través de los ojos de Caldas en la cual al contrario de fraccionar, se establece una apuesta de la integralidad de los elementos territoriales en paisajes propios del mundo latinoamericano. 


\section{Los cronistas del siglo XVI y XVII y la Palabra Oro, configurando el paisaje}

Desde la llegada de Colón al continente, hacen su aparición los cronistas como personajes cuya importancia es bien vista en Europa, por ser en últimas, la principal audiencia donde se despertó la expectativa por los escritos que dibujaban la apariencia, vida y costumbres del hombre americano y su mundo natural.

Además de la exhaustiva tarea de transmitir una imagen del nuevo mundo los cronistas se encargaban a su vez de narrar las peripecias de los expedicionarios peninsulares que exploraban el territorio recién descubierto, en busca de la riqueza que no tenían en sus lugares de origen o en otros casos por el ansia de la aventura y el protagonismo que les daba una importancia ante sus conocidos del otro lado del mar.

América era el escenario perfecto para realizar lo imposible y respirar lejos de la decadencia del viejo mundo. Un territorio donde las naciones europeas encontraban un modo de fortalecer sus intereses económicos y ampliar sus posesiones. A pesar de la renovación intelectual del renacimiento, era parte de la cotidianidad y el discurso circulante, la mixtura feudal de la tenencia de la tierra como fuente de supremacía sobre los otros, sumado a este ejercicio de propiedad privada, el auge del valor de cambio y la consolidación de la mercancía y la moneda, complejizaron al máximo los utillajes y prácticas sociales de los europeos.

Instituidos en este contexto ideológico y social llegaban los conquistadores a chocar con un medio geográfico que no conocían, y cuando se habla de geográfico implica por extensión la unión de la naturaleza y pobladores. Elaboraciones intelectuales, formas de producción e intercambio económico dentro de criterios diferentes; en resumen, una cultura ajena a lo que se vivía al otro lado del Océano Atlántico.

En el siglo xvI las expediciones ubican sus respectivos puntos estratégicos en donde se organizaban las rutas en la búsqueda de nuevos territorios y riquezas. Para las dos primeras décadas de este siglo ya existía entre los conquistadores el rumor de El Dorado, el mito que llevaría a la frenética pesquisa de los templos adoratorios, viviendas, tumbas y hasta fuentes de agua vecinas a los asentamientos indígenas.

Parte de la consolidación de estas leyendas viene de textos y relatos, de los cuales son conocidas las obras de dos cronistas como son: Fray Pedro Simón y Lucas Fernández de Piedrahita. Del primer personaje nacido en 1574 en San Lorenzo de la Parrilla, se puede decir que fue un religioso cuya elaboración erudita le permitió hacer una serie de descripciones y reflexiones sobre las expediciones en tierra firme durante sus oficios en el Nuevo Reino. Su llegada a Santafé es registrada hacia 1604, donde el historiador Juan Friede resalta que no 
era el deseo de Simón el de venir a tan lejanas tierras sino por convencimiento de Fray Luis de Mejorada para trabajar en oficios administrativos (Friede, 1981).

El papel de este cronista fue importante por cuanto sus descripciones de la tradición indígena han permitido la evocación de aspectos tan importantes como la tradición oral. Hay que tener en cuenta que su juicio se adecúa al pensamiento del momento, las afirmaciones sobre las culturas que habitaban los territorios y la cotidianidad en su relato pueden ser analizadas desde muchas perspectivas.

Siguiente texto, es el relato de la traición al cacique Guatavita:

Sucedió pues en aquella edad que entre las mujeres que tenía estaba una de tan buenas partes en sangre y hermosura que así como en esto excedía a las demás también las excedía la estimación que hacia ella tomó el Guatavita. Lo cual, no advirtiendo la cacica como debiera, hízole traición con un caballero de los de la corte y no en tan secreto que no llegara a los oídos del marido. El cual puso tan buenas diligencias en haber a las manos al adultero, que presto le cayó en ellas, y desde ellas en aquel cruel tormento de muerte que usaban en tales casos, como era empalarlos, habiéndole primero hecho cortar las partes de la punidad, con las cuales quiso castigar a la mujer sin darle otro castigo que dárselas a comer guisadas en los comestrajes que ellos usaban en sus fiestas, que se hizo por ventura sólo para el propósito en público, por serlo ya tanto el delito (Simón 1627/1981: 324).

Junto a estos relatos fantásticos, los cronistas describieron el camino de los expedicionarios que atravesaban la maraña y cuanto obstáculo se imponía a su necesidad de llegar a los caseríos y lugares que ofrecían, comida, oro y una buena estadía.

Cuando se repasan las páginas donde los cronistas de indias cuentan la historia de nuestra conquista, se observa que las notas dominantes de esa grandiosa epopeya fueron el valor, la codicia, la desorganización y el hambre.

Y así iban errando de aquí para allá y de allá para acá, siempre con la esperanza de hallar mucho oro para salir de pobrezas, pero teniendo que amansar mucho el estómago y sustentarse con lo que encontraban (Lemaitre, 1998: 14).

La llegada a la Sabana de Bogotá no fue fácil. En su paso, la ruta de Quezada dejaba sucesos llenos de heroísmo y otros de infamia, situación que no sólo ocurría con Jiménez sino con otras expediciones relatadas por los cronistas, donde era el medio y la excentricidad de sus pobladores los que influían en el difícil acceso a los territorios del interior:

[...] para los españoles del renacimiento [...] que se vinieron a este Nuevo Mundo, la conquista, con todas sus brutalidades, era un hecho natural, casi una misión que Dios les había encomendado, y todo aquel ruido de armas, todo aquel torrente de sangre, todo aquel saqueo implacable, no les parecía sino el choque lógico entre los 
paladines de la buena causa de Dios y de la civilización, con los que, dejados de la mano de Él por alguna causa ignota, pertenecían al imperio de Satanás (Lemaitre, 1998: 25).

Esta serie de percepciones sobre los indígenas y su entorno, contribuyeron a que los cronistas reprodujeran una idea de paisaje macabro y salvaje, representación que se manejó sobre el nuevo mundo en Europa. Sólo hasta la descripción y reflexión de Humboldt, su visión romántica y su trabajo geográfico se comenzó a transformar la visión que afirmaba al poblador americano y su entorno como lo bestial e indómito.

A través de sus escritos, los cronistas hicieron la descripción de los lugares que se descubrían, otorgándoles la importancia según las experiencias de los expedicionarios en su encuentro con ellos. Los ríos, montañas, lagunas y pasos entre otros fenómenos del espacio ya se comenzaban a jerarquizar y a cobrar importancia.

[...] todas las aguas que entran por una parte y otra de las serranías que no son pocas en este valle de Bogotá, no tienen más que una salida por lo último de la parte del sur oeste, donde se junta de todas un copioso río que llaman Bunza.

Este halla una estrechura, ya al desembocar al valle que llaman de Tequendama, por entre dos piedras tajadas y otra que está en medio de ellas, con que hace dos canales tan estrechos que muchas veces, no bastando a dar salida a las muchas aguas que por allí van a embocar (en especial en tiempo de invierno), rebalsan atrás, con que se anegan grandes pedazos de la sabana en especial cerca de los pueblos de Bosa, Hontibon y Bogotá [refiere el ultimo al cercado indígena] con que quedan por todo lo más del año grandes anegadizos. (Simón, 1627/1981: 379).

Uno de los ejemplos más claros de la jerarquización, es el desarrollo de la cartografía, donde se tiene como senda de referencia el río Magdalena, ruta principal desde la primera incursión en el interior, sin contar las cartas que tenían su fundamentación en la organización estratégica y militar de los poblados de la corona. La circulación de los capitales extraídos y la movilidad de las mercancías y pertrechos para las expediciones, fueron configurando la representación de los lugares: desde las minas de esmeralda de los muzos y somondocos hasta las de sal en la sabana pasaron de las leyendas a los relatos y la cartografía.

\section{La herencia recibida por Caldas: recopilaciones y diccionarios geográficos, relatos que retoman otros relatos de paisaje}

Lo que Caldas encuentra como acervo para preparar sus análisis y mediciones es un repertorio de transcripciones. Característica de esta época, es la tendencia a transmitir varias veces el mismo cuadro de la crónica. Uno de los casos encontrados es el de Fray Pedro Aguado (nacido en Valdemoro, 1513), monje 
franciscano, que llega a América hacia 1561 a ejercer el trabajo como doctrinero hasta 1575, cuando abandona el Nuevo Reino en calidad de procurador de su orden (Friede, 1956).

Por medio de diversos documentos el religioso pide su traslado a Santafé pero en ese momento no logra su objetivo, quedándose en España donde redacta y ordena los apuntes del fraile Antonio Medrano dejados por éste último en la provincia, cuyo contenido refieren la historia y descripción del Nuevo Reino de Granada. Esta serie de escritos fueron completados y preparados para su publicación en la Recopilación Historial hacia 1582:

[...] la obra que dejó Medrano estaba en estado muy avanzado, casi para ser publicada. Esto no excluye que Aguado hiciera en ella correcciones, omitiera algunos párrafos o añadiera otros, ni que ordenase lo compuesto a su gusto y que completase aquellos trozos que así lo exigían. Pero todos estos trabajos eran esencialmente de redacción, forma, y esto lo confirma tácitamente el propio Aguado cuando teme que su aportación personal no sea bastante apreciada por el futuro lector (Friede, 1956: 9).

Medrano y Aguado plantearon el ejercicio de trabajar sobre el relato del otro mostrando en su descripción del paisaje hechos y lugares a través de instantáneas muy particulares:

[...] verdaderamente tuvieron esta vez puestos en grande riesgo los indios a los españoles porque además de ser ellos en mucha cantidad favorecíalos el sitio en que se recogían, que eran unos lagos y pantanos hechos de las inundaciones del río de Bogotá, en medio de los cuales había ciertos isleos donde los indios se recogían, y desde allí salían a acometer a los españoles [...] en estos lagos que demás de ser algo hondables, porque daba el agua de ellos a los pechos, eran muy cenagosos y llenos de medaño y tierra [...] (Aguado, 1582/1956: 300).

La visión del mundo en las crónicas era una mezcla del afán de una fidelidad a los hechos en dialéctica con el discurso de las comunidades religiosas, además de las órdenes evangelizadoras a las cuales servían estos sabios aventureros que terminaban involucrados en las exploraciones a territorios indómitos.

Lucas Fernández de Piedrahita nació en Santafé en 1624 y su vida de religioso lo llevó a terminar sus días como obispo en Panamá por el año de 1688. Sobre él, afirma Guillermo Hernández Rodríguez, que su obra Historia general del Nuevo Reino de Granada, producida en España hacia 1678, se basó en gran parte en los escritos circulantes de Jiménez de Quesada y de los trabajos de Fray Pedro Aguado, Antonio Medrano y Juan de Castellanos (Hernández, 1949). "[Bogotá indígena] yace fundada en el centro de un llano que tiene de latitud diez leguas y más de veinte de longitud. Cércala en contorno lagunas, diques y brazos del río Funzha que hazen sus territorios anegadizos" (Fernández de Piedrahita, 1678/1986: 25). 
Esta saga de cronistas utilizaba la trascripción de relatos, acontecimientos y memorias como medio eficaz para reproducir las ideas y las visiones que se imponían, la importancia de esta serie de crónicas es que armaron el panorama del mundo americano y consolidaban en su conjunto todo un sistema de símbolos sobre los cuales se apoyaron aquellos que intervenían de un modo u otro en la cotidianidad colonial. La significación de dichas versiones de la historia fortalecieron las narrativas de habitantes y visitantes del Nuevo Reino.

Aunque como lo han señalado historiadores como Roger Chartier (2008), el analfabetismo hacía de la posesión de los libros un privilegio de algunos grupos que se recreaban en las artes de la edición y publicación de los textos. El novedoso invento de Gutemberg vendría a ser fructuoso con la revolución en el siglo xvIII que hizo del impreso el principal medio de difusión de las ideas abolicionistas y antimonárquicas.

La conquista y varios años del siglo XVII son reseñados por Juan Rodríguez Freile en su obra El Carnero. Una pieza literaria representante de la literatura hispanoamericana inmersa en la cotidianidad de la sociedad santafereña, la cual ha sido tomada por los historiadores como una de las referencias irremplazables cuando se habla de la colonia.

Estaba el río Bogotá tan crecido con las muchas lluvias de aquellos días que allegaba hasta una hacienda que está bastante distante llamada Techo, junto a lo que agora tiene Juan de Aranda por estancia. Era de tal manera la creciente, que no había camino descubierto por donde pasar y para ir de esta ciudad a techo había tantos pantanos y tanta agua, que no se veía por donde iba (Rodríguez Fraile, 1638/1997: 137).

En este escrito el paisaje es visto desde los ojos de un habitante de la ciudad que de una u otra forma se involucra en el contexto y lo describe procurando ser fiel a los sucesos e ideas que se presentaron en la época.

Más de un siglo después, el oficial Antonio de Alcedo permite evidenciar cómo se llegaron a consolidar las representaciones del medio americano en Europa. Su Diccionario Geográfico Histórico de las Indias Occidentales o América publicado hacia 1752 fue realizado con base en los relatos que el escuchaba o leía de los expedicionarios una vez que retornaban a la península. En el mismo texto se resalta que el autor nunca viajó o conoció los territorios descritos e inventariados en su obra.

Una tradición de referencias que se puede ver tiempo después en Ibáñez o Cordovez Moure en el siglo XIX, donde el escritor se centraba en su versión de los hechos y su descripción de los lugares estuvo sujeta además de los eventos que ocurrían en ellos, a sus concepciones y dictámenes sobre los asuntos. Notas al margen que pasaban a ser el centro de los relatos y descripciones. 
Gracias a narraciones como la llegada de Quesada al territorio o los amores del comendador Auncibay con doña Jerónima (texto que relata la historia del primer puente que se construyeron sobre el Río Bogotá) se pudo extraer una versión de los paisajes, donde estas historias llegaban a suceder y sin querer la representación de los momentos llevó a concretar las subjetivaciones y las representaciones del espacio de la época.

\section{La aparición de las descripciones de Francisco José de Caldas: el paso de lo colonial a lo republicano}

El alma del hombre suramericano está ligada al paisaje, mencionó hacia los años cuarenta, Eduardo Caballero Calderón, del mismo modo frente a la vida de Caldas podría decirse que estuvo atada al paisaje natural que tanto le emocionó como científico, pero a su vez a la ficción que este oficio tejió alrededor de sí mismo, al permitirle a Francisco convertirse en "el Sabio" (mote con el que se le identifico) lo que implicaba una doble agencia sobre su persona: por un lado el compromiso de su prestigio y fama científica y por otro lado la virtud de un hombre íntegro y consagrado a su profesión.

Este doblez en la personalidad de Caldas nos habla de su ser sujeto, caracterizado por unas pasiones que por la densa descripción de biografías e incluso su propio testimonio epistolar, fueron más tenues en los intereses de la carnalidad y la banalidad humanas que en el cultivo de una especie de sacerdocio del conocimiento.

El escritor Luis Eduardo Nieto Caballero escribe hacia 1938:

Caldas era un sacerdote de la ciencia y hubiera sido ejemplar como sacerdote de la religión. [...] Consiguió esposa como quien consigue un telescopio, una manta, un caballo, encargándola a un amigo, para quererla sin conocerla, para tenerla quizá como ama de llaves, como enfermera, sin el arrebato del amor que entra por los ojos y que desencadena la más sublime tempestad del espíritu (Nieto, 1984: 32).

Esta imagen crítica del científico permite ver la permanencia simbólica de un ascetismo del intelectual escolástico que influyó en los imaginarios criollos andinos, quizá por esa mezcla de la moral cristiana con la devoción por la ciencia y sus quehaceres. En definitiva, la creación de una ficción que rodeó el aura de nuestros pioneros científicos colombianos.

Es vox populi que Caldas ya estaba trabajando en las exploraciones de reconocimiento, biofísico y astronómico de los territorios nacionales incluso antes de la intervención de Mutis y Humboldt. Podría decirse que el trabajo fue solitario y con resultados que fueron consignados en los informes publicados en principio en el Correo Curioso, el semanario del Nuevo Reino de Granada, fundado y bajo su dirección, fue espacio de confluencia intelectual de los criollos intelectuales de la 
época. En este escenario la preocupación por el territorio y el paisaje llenaron páginas enteras de observaciones sobre la geografía y el clima de las regiones.

La Nueva Granada era cuna de cronistas, políticos y científicos, que en cierta medida reunían las tres visiones y se consideraban finalmente sabios. Tal capacidad para pensar holísticamente la sociedad les facultaba para explorarla simbólicamente y hacer de ella un ejercicio de interpretación de sus acontecimientos y actores. De tal manera que cuando José Celestino Mutis aparece en escena, hay toda una comunidad de aficionados y letrados al mismo tiempo al conocimiento, ese que detentaban los textos científicos y que en ocasiones terminaban en censura por parte de la iglesia, máxima autoridad moral e intelectual en la época.

Por eso no es de extrañar que, ante una predominante formación religiosa, Caldas construiría un repertorio moral y ético fundado sobre las verdades que el dogma y La Biblia había formado en su persona. La aparición de Mutis para Caldas se presentó como una revelación y una oportunidad para crecer como científico, desde 1782, Mutis dirigía la Real Expedición Botánica y administraba los recursos del Virreinato correspondientes para la exploración y clasificación de especies. Atraído por los hallazgos precedentes de Caldas como el hipsómetro y las observaciones astronómicas, Mutis encontró en el joven Payanes a un aliado científico que permitiría agilizar la revisión de la naturaleza neogranadina de allí el encargo de tomar y analizar la diversidad de la vegetación de Quito, escenario en donde Caldas se cruzaría con el científico prusiano Alexander von Humboldt de quien sostenía muchas expectativas pero que dejaría en Caldas vastas decepciones desde lo personal y lo científico. ${ }^{1}$

Entre las reflexiones sobre el paisaje, en primer lugar se reflexiona largamente sobre las vicisitudes de desarrollar un proyecto científico en el territorio, en sus cartas a Mutis, Caldas narra que ha tenido que recurrir a mercadear para proveerse de recursos y lograr conseguir instrumentos y otros menesteres, en esta misiva agradece el obsequio de instrumentos que Mutis hace llegar pero lamenta el soslayo de la nobleza virreinal y santafereña que inspiran en él un sentimiento político de discrepancia con la marginalización del sabio español por cuenta del cambio educativo y la supresión de la filosofía natural, que Caldas llama Filosofía Botánica la cual se impartía en el Colegio Mayor de nuestra Señora del Rosario (hoy Universidad del Rosario), es un reclamo académico a las cegueras de la época, a la escasez de recursos y al poco interés de quienes administran, por estas tareas de la ciencia, desde Quito el 6 de abril de 1802 dice:

1 Al respecto hay trabajos que toman el conflicto Caldas-Humboldt desde la competencia científica tanto como la disyuntiva sobre las prácticas homosexuales del segundo que para la sociedad recatada santafereña y la formación conservadora del payanes era una afrenta a las buenas costumbres (Arías de Greiff, 2001, 1968 y 1967). 
¿cuál es el hombre que derrama el oro y la plata a manos llenas para que un joven viaje, se instruya y vuelva a ser útil al común? ¡Ah! ¡Que raros son estos genios bienhechores! ¡Que ingratos hemos sido con este ángel tutelar de la nueva Granada! ¡Cuantos años ha que trabaja en ilustrarnos en hacernos felices! Ignorantes hasta no percibir vuestro merito, vuestra sabiduría, una sabiduría que ha resonado en los ángulos más retirados de la Europa (1975: 90).

Parte de la protesta, por presupuesto y espacios científicos representaba también el cambio en las visiones sobre el territorio como respuesta a una trayectoria de informes de explotación. Fuentes como las "Relaciones de Mando", informes de obras públicas y actas de la Real Audiencia, contienen una serie de datos que permiten leer esta clave de lecturas extractivas del paisaje.

En una relación de Mando de un Virrey se puede encontrar desde el dinero recogido por concepto de aduanas, hasta el descubrimiento de plantas valiosas para determinados usos. Presupuestos, resultados, impuestos entre otros asuntos son tratados en esta clase de materiales. Por ejemplo en Caballero y Góngora se lee: "[...] en mi concepto lo que hace el principal ornamento y gloria de la Expedición Botánica es la invención del té de Bogotá, preciosísima planta de tanto uso en Asia y Europa, y no poco en América, y que hasta ahora se había creído producción exclusiva de la China" (Caballero y Góngora, 1789 en Giraldo, 1954: 112).

Con relación al análisis espacial, en estos documentos se develan las funciones que determinaron históricamente la distribución de las formas de explotación y los centros que permitieron el desarrollo de las fuerzas productivas del país históricamente. La motivación de esta clase de informes fue fortalecer la base de datos de la corona española sobre los movimientos socioeconómicos de las colonias. Un total control que beneficia directamente en cuanto a las exportaciones y la acumulación debida de la riqueza de los habitantes. Desde una lectura más simbólica, la necesidad de ostentar un poder legítimo requería responder con obras, una demagogia política que aún se utiliza, de allí que hay relaciones de Mando que son más homenajes al mandatario y sus acciones, que un informe de traspaso de poder entre funcionarios.

Mientras los virreinatos dibujaban para inventariar, Caldas era parte de un movimiento diferente, la influencia de la ilustración francesa y la autonomía de científicos realistas como Mutis permitieron el desarrollo de actividades científicas como la Botánica, la Astronomía y la Geología entre otras razones de coyuntura socio política en el viejo continente, movieron a los viajeros a aventurarse en el territorio americano:

A partir de la revolución Francesa el mundo occidental fue muy entusiasta con las ciencias. Napoleón dio impulso definitivo a su promoción fundamentalmente con su 
inusitado viaje a Egipto. El mundo de la ilustración política que había provocado la revolución burguesa estaba absorto y pendiente de los secretos de la fauna, de la flora, de la furia de los volcanes, de las insospechadas expediciones (Piedrahita, 1997: 67).

Entre los más reconocidos expedicionarios se encuentra Alejandro von Humboldt, un aristócrata prusiano, que junto al botánico francés Amadeo Bondpland, hicieron una serie de viajes al continente americano con el fin de estudiar el contexto natural de los territorios y dar testimonio de la vida y costumbres de estas regiones. Escribe Humboldt sobre el Salto de Tequendama:

[...] el aspecto del Salto es infinitamente bello. Yo lo vi primero de lado cuando me coloqué estirado sobre el banco de arenisca que el río deja en parte seco. Posteriormente lo observé por delante a alguna distancia [...] las aguas están mermadas -y es así como las he visto- el espectáculo tiene más movimiento. El peñascal presenta dos tajos o salientes, uno de 30 pies, otro de 180, que producen sucesivas caídas al termino de las cuales todo se deshace en espumas y vapores. [...] la conformación del sitio dificulta sobre manera una medida exacta de la altura del "Salto". No basta dejar caer verticalmente una piedra: para que ella no dé en las salientes de la roca, hay que imprimirle una determinada fuerza de impulsión que a mi parecer falsea el experimento (Humboldt, 1808 en Villegas Ed, 1994: 92).

Según varios historiadores, la visión humanista del alemán contribuyó a cambiar la mentalidad que se tenía en Europa con relación al hombre americano, donde el buen salvaje (término acuñado de la corriente francesa del siglo XVIII) pasó a representar un individuo social de un contexto diferente. Cabe aclarar que la tendencia del pensamiento científico determinista estaba en todo su auge y que la influencia de esta corriente se proyectaba en todos los estudios sociales o filosóficos que trabajaban en referencia al mundo americano. Ahora, frente a ese humanismo proclamado por la ciencia eurocéntrica vale la pena apartarse un poco, pues las lecturas de Humboldt sólo son parte del inmenso estilo y repertorio de autores como Linneo, no hay tal innovación en la descripción micrométrica.

Aquí es donde radica una reinvención de la visión científica del paisaje, la manera en que Caldas logra recoger en su descripción la exactitud de lo medible con la calidez de lo sensible, es el payanés quien de forma visionaria recogería lo que al principio de este texto se ha esbozado desde Fernand Braudel, Milton Santos y Agustín Berque, a saber, la capacidad de leer el espacio/paisaje en toda su extensión reconociendo junto a sus valores físicos, sus valores simbólicos.

Pero él, cegado por el mismo eurocentrismo que aún nos arrebata la seguridad epistemológica se inclina a referenciar las exploraciones de los europeos. En el marco de la Expedición Botánica evalúa el Salto del Tequendama uno de los paisajes vistos con asombro por el prusiano Von Humboldt. 
[sobre el Salto del Tequendama] En 1807, quise yo también hacer mis tentativas con esta celebre catarata. Usé, como Humboldt, el descenso de los graves y hallé constantemente que estos gastaban 6 instantes en bajar (Uribe White, 1981: 166). De aquí deduje que la cascada tenía 219,9 varas de altura. [...] A más de esto, en Tequendama no se puede asegurar el observador del momento preciso en que el grave toca la parte inferior de la cascada... la altura perpendicular de esta cascada es de 78 toesas (183.60 varas) termino suficiente para algunas nuevas producciones (Caldas, 1942: 213).

Pero dejando a un lado la descripción biofísica, posteriormente Caldas no escatima prosa para referenciar el paisaje:

Se agolpan majestuosamente las aguas al borde del precipicio; de allí se descubre un abismo, una profundidad prodigiosa que inspira a quien la observa un secreto asombro, y si podemos hablar de esta manera, cierto horror deleitable. La caída del río es muy pintoresca, o más bien la pintura es incapaz de representarla: una taza de piedra recibe el primer ímpetu de las aguas, que se resuelven al a vista en una especie de rocío, bajando luego con el mayor ímpetu al extremo de la cascada (Caldas, 1942: 214).

El interés de Francisco José de Caldas era el de cultivar los conocimientos y lograr una base de datos sobre la vegetación, en una Geografía de las plantas que implica una mirada distinta del medio natural a la extractiva imperante:

[sobre la necesidad de cambiar la mirada de la ciencia] Pero el hombre, sensible a las obras de la imaginación, se complace en hermanar la Geografía de las plantas con las producciones de la fantasía. La contemplación de la naturaleza, la vista de los campos y de los bosques causa una dulce sensación, muy diferente de la impresión que hace el estudio particular de un ente organizado. En este, el por menor es el que interesa y alimenta nuestra curiosidad; y en aquella, son las grandes masas las que agitan nuestra imaginación (Caldas, 1942: 41).

Esta lectura del paisaje se vería tenuemente materializada por Humboldt, quien reconoce tibiamente los aportes de Caldas en compensación de su marginalización del viaje a las exploraciones de Perú y México. Esta Geografía de las plantas vestida con los aportes de los americanos pero maquillada con el rotulo europeo, sería traducida por Jorge Tadeo Lozano en el Semanario del Nuevo Reino de Granada, pero la soberanía sobre el documento y sus descubrimientos estuvo en el ojo del huracán de la opinión en el siglo XIX:

Caldas fue desgraciado. Igual desengaño sufrió con su Geografía de las plantas, sistema de que fue único y exclusivo inventor, y de que igualmente se aprovechó Humboldt. Parece, según estoy informado que un distinguido botánico español, el 
señor Villanova, reivindica para Caldas la gloria de esta invención muy anterior a la época en que el Barón escribió su obra que lleva el mismo título (Caicedo 1950: 101).

Con esta falta de apropiación sumada a las masacres de la independencia implicaron un atraso y un desconocimiento del humanismo y el naturalismo donde el positivismo se impone como visión hegemónica de todos los fenómenos. El paisaje es medido, cuantificado y registrado minuciosamente a fin de mirar causas, efectos y procesos que lleven a la comprensión de los territorios en sus unidades naturales. La descripción de Caldas del Salto de Tequendama es solo una muestra de la vasta obra del Semanario y de otras producciones donde reúne las visiones cuantitativas y cualitativas del paisaje, en ellas se desarrolla desde la medición de la anchura de ríos, valles y montañas, el inventario de las especies y los astros en un dialogo natural con la poética de los lugares, fruto de las sensaciones más íntimas.

\section{La herencia de Caldas y su tiempo en las visiones del paisaje colombiano}

Los avatares de la política (1810-1820) lograrán robar el sueño de la configuración de la cartografía natural, una obra que hubiese contribuido a tiempo al desarrollo del país después de la independencia. Un paso decisivo para el movimiento de la libertad criolla, pero un retroceso para la ciencia por cuanto el interés de España hizo sacar del país la obra de la expedición, dejando nuevamente en incertidumbre la geografía del territorio: "En 1816 en ciento cuatro fúnebres cajas, se ocultó para la ciencia universal la obra múltiple de Mutis y de sus discípulos neogranadinos. Depositada como en un panteón, en el gabinete del Jardín Botánico de Madrid [...]" (Hernández de Alba 1968: XXI).

En este sentido comienza el juego literario sobre el espacio del mundo romántico, la vida del aventurero empieza a llevarse celosamente en los diarios de viaje, un estilo de escritura que permitió la narración subjetiva a través de elementos evocativos. En Colombia vivieron juntas las miradas de los viajeros extranjeros y los nacionales que influenciados por su época se dieron a la tarea de escribir: en este sentido se puede hablar del texto titulado: Colombia: being a Geographical, Statistical, Agricultural, Comercial and Political account of that country (Londres, 1822), publicado por Baldwin, Cradock y Joy como uno de los textos pioneros de esta modalidad literaria. Entre otros que siguieron la influencia se puede presentar el de Salvador Camacho Roldán llamado Notas de Viaje (Colombia y Estados Unidos) (Bogotá, 1890), obras que combinaron la descripción de los lugares con la historia y la descripción del contexto en que ocurrieron estos viajes. Algunos se caracterizan por ser más específicos como la obra de Alfred Hettner en 1882 con su estudio La Cordillera de Bogotá. 
Finalmente, Caldas estratégicamente ubicado en las postrimerías del siglo XVIII y principios del XIX es prueba del interés científico, que heredero de la tradición científica de Linneo y Mutis y la tradición extractiva del modelo colonial, se centró en las observaciones y cálculos directos desde ciencias como la Botánica, Astronomía, Hidrología, Geología y otras disciplinas puras, pero que desde la experiencia sensible fue complementándose. La intención es la construcción unificada del paisaje tanto en su dinámica natural como en su contexto social; solo es a través de esta serie de trabajos, descriptivos e informativos realizados que se comienza a dar forma a la imagen de la sabana de Bogotá, entre otros territorios.

Hacia la tercera década del siglo xIX se da una fuerte tendencia a la generación de una serie de escritos anecdóticos donde se combinan la cotidianidad, con los elementos del paisaje; es decir, se consolida una descripción pintoresca de las regiones del territorio.

[...] me adelanté y durante la bajada fui recompensado con el paisaje que de vez en cuando se observa sobre el río Bogotá, que buscó su camino a través de espesos bosques y era visible de vez en cuando. En el vado del río me di cuenta de que éste apenas tenía una profundidad de dos a tres pies (Cochrane, 1824/1994: 232).

De diferente procedencia, aunque en su mayoría francesa, estos exploradores hicieron de los paisajes, relatos vivos llenos de observaciones que iban desde el más estricto rigor científico hasta la más subjetiva nota de sensibilidad, hacia el medio y las situaciones. La lista de los viajeros extranjeros es larga, sin embargo, existen condiciones comunes que los convocaron a venir a la Nueva Granada, por ejemplo, el doctor Le Moyne, vino al país en función diplomática, al igual que el coronel Hamilton Potter, entre otros. A estos expedicionarios, la importancia de describir lo que vivían en estos viajes les servía como tema de reuniones y artículos en periódicos de Europa o como relatos asombrosos en reuniones sociales. La moda era ser viajero, pero para ello se necesitaba dinero y empeño en soportar los problemas del camino.

El caso de Stuart Cochrane resulta curioso, pues cuando venía del camino de Honda hacia Bogotá su guía siempre iba ebrio, situación que lo envolvía en problemas durante el viaje, lo irónico es que nunca lo despidió pues este mismo lo acompañó al salto del Tequendama y en el camino de regreso al Magdalena. De allí que en sus descripciones hace referencia a la negligencia de su ayudante a quien era difícil encontrar en sano juicio.

A las 11 de la mañana paramos en una fonda para desayunar, me di cuenta que nuestras mulas estaban extenuadas y de que no estaban en condición de soportar el viaje, por lo que pregunté si era posible conseguir unas que estuviesen descansadas; el peón, que ya para ese momento estaba más sobrio, contestó afirmativamente, 
pero olvidó mencionar la distancia que tendríamos que recorrer para obtenerlas (Cochrane, 1824/1994; Villegas Ed, 1994: 94).

La visión del paisaje de estos viajeros y sus observaciones no era muy diferente a la de los intelectuales sabaneros; editoriales como la del Banco Popular se han encargado de publicar obras como Museo de cuadros y costumbres, donde se ubican descripciones como las de José María Salazar y Eugenio Díaz, entre otros.

El viajero tomaba nota de los paisajes y las gentes, gran parte de ellos contribuyen notablemente en la narración de la historia política colombiana, a la cual le dedican buena parte de sus memorias y sus apuntes de viaje. Esta clase de escritos demuestran cómo la situación que atraviesa el país influye en la mirada del visitante, además de ser parte de su cotidianidad cuando entra a hacer contacto con el medio social en que es recibido.

Hacia 1839, el congreso bajo iniciativa de Tomás Cipriano de Mosquera, mira la posibilidad de realizar Una obra geográfica sobre la Nueva Granada (Schumacher, 1988: 127), con base en los mapas y planos referentes al antiguo Virreinato de Santafé, procedentes de la familia del ingeniero Bauzá, y del Depósito Hidrográfico Español. Delegó la recopilación de los materiales a Agustín Codazzi, quien antes de finalizar el gobierno de Mosquera en 1849, entregó un informe donde su postura se puede concretar en la siguiente forma:

Codazzi [...] no pudo conceder valor alguno a tan heterogénea combinación de materiales cartográficos. Pensaba como Caldas que lo valioso se desmejora si se junta con lo anodino. Resultaba, así mismo, prácticamente imposible integrar mapas especiales de Caldas y Roulin con mapas generales de Restrepo y Acosta, y mapas marinos de Fidalgo y Bauzá (Schumacher, 1988: 128).

Mosquera recalcaba en la descripción de las 36 provincias con su cartografía, así que al asumir el poder José Hilario López, Codazzi continuó con el apoyo del proyecto de elaborar la geografía general. Al coronel italiano se le asignó un sueldo de 3321 pesos, además de algunos instrumentos y libros, posteriormente se llegó a un acuerdo con Manuel Ancizar para que fuera el estadístico y relator del viaje (Schumacher, 1988), de esta forma se conformó la Comisión Corográfica cuyas cartas carto-geográficas constituyeron la principal base de datos sobre el territorio, que solo se renovó con la ortofotografía y la tecnología a mediados del siglo xx.

La Comisión Corográfica trabajó bajo las siguientes labores estipuladas en el contrato firmado con él secretario del interior:

Las descripciones de las provincias y de sus cantones serán la explicación detallada de todo lo concerniente a la geografía física y política de la respectiva provincia y de sus cantones, con minuciosa expresión de los limites, configuración, extensión, ventajas locales, serranías, ríos, etc.; y con inclusión de noticias tan cabales como sea 
posible adquirirlas, acerca de las producciones naturales y manufacturadas de cada localidad, su población, y estadística militar; comercio, ganadería, plantas apreciables, terrenos baldíos y su calidad; animales silvestres, minería, climas, estaciones, y demás particularidades que sean dignas de anotarse (Restrepo, 1999: 33).

Con esta serie de recomendaciones sobre lo que requería el gobierno del trabajo de Codazzi, se consolida la visión del paisaje que duraría hasta entrado el siglo xx. El coronel italiano había aceptado dirigir la comisión a la edad de 57 años, razón por la cual tuvo la colaboración total de sus estudiantes quienes dependían únicamente de su maestro (Schumacher, 1988). La intención del geógrafo fue de formar ingenieros civiles y militares que dieran cuenta del país y que desde su educación colaboraran con los pobladores a mejorar las condiciones de vida.

Los resultados de la Comisión Corográfica que comienza en 1850 y finaliza en 1859 son consignados en las cartas oficiales de la República y sus descripciones publicadas en varios compendios de Geografía física y política, que a lo largo de las décadas siguientes realizaron políticos como Felipe Pérez, Manuel María Paz e ingenieros como Manuel Ponce de León e Indalecio Lievano (Restrepo, 1999: 35).

En cuanto a la Geografía humana y su crónica o la descripción que hizo referencia a las costumbres, relatos de viaje y hechos durante la Comisión, se pueden encontrar en la Peregrinación de Alpha, texto publicado por Manuel Ancizar primero en forma de folletín y posteriormente en la década de 1880 es editado como libro. El trabajo de Ancizar es reconocido por la buena descripción de los paisajes y el trasegar de los caminos en medio de los cuentos de los pobladores y las reflexiones que hace el autor sobre lo que observa en los lugares que visita.

A poco llegamos a un arroyuelo claro y purísimo que baja de las peñas del Fusca y atraviesa el camino en demanda del río Funza para precipitarse con él hacia el abismo del Tequendama. La agreste belleza del sitio y murmullo de las límpidas aguas que bajan camino por entre rocas sombreadas de floridos arbustos, nos obligaron a detener el paso y beber en aquella fuente solitaria, no enturbiada hasta allí por la mano del hombre, sometida a cauce artificial más adelante, turbia y revuelta con otras aguas después, hasta caer tributaria en el vecino río y lanzarse con él en las profundidades del Salto. (Ancizar, 1880/1970: 34).

Para muchos de los viajeros y científicos las condiciones del país daban cuenta de los niveles de atraso e ignorancia de los pobladores de estas tierras, ya que consideraban que el ambiente de trópico y la topografía del territorio colombiano retardaban los adelantos que surgían en otros lugares del planeta, especialmente de Europa.

La naturaleza nos ha rodeado de inmensos obstáculos para el desarrollo rápido de las fuerzas sociales, enclavando nuestro pueblo en el seno de una complicada red de 
cordilleras, levantadas donde quiera como jigantescas murallas para impedir por mucho tiempo a lo menos, el cambio de las ideas, la liberación de los valores circundantes-el movimiento de la sociedad en todos los sentidos.

Todo está aquí por explorar: el comercio languidece o se mantiene estacionario; la navegación mejora poco; la minería solo progresa en Antioquia; la agricultura avanza lentamente; las vías de comunicación faltan; i los recursos que la industria humana a creado para disminuir el trabajo del hombre i centuplicar su fuerza con la de los ajentes (sic) naturales apenas son conocidos entre nosotros bajo la forma de teoría. (Samper, 1857: 3).

En este punto, las fuentes se entrelazan y se transcriben como en las crónicas coloniales, las descripciones que son réplica del trabajo de la comisión corográfica con las memorias de personas influyentes que se dieron a la tarea de viajar por el territorio sin compromiso alguno, como es el caso de lbáñez y su obra Bogotá y sus inmediaciones, además de Cordovez Moure con sus Crónicas de viajes sobre Colombia y Europa.

La memoria o diario, cuyos datos hablaban de las características físicas del paisaje (alturas, tipos de suelo, etc.) se combinaban con las anécdotas de viaje y la tradición oral que se registraba en los lugares, de esta forma se describía el país. Esta tendencia permaneció entre 1820 y 1920 cuando se renuevan las nociones sociales del poblador americano y principalmente con la masificación de la fotografía y los medios visuales, a partir de los cuales emergen nuevas formas de narrar el espacio.

Caldas contribuyó en esta escuela de la lectura del paisaje. Sus aportes hoy se han amalgamado en diferentes espacios de la ciencia, soslayando sus llamados al orden, esas cartas extensas a Mutis donde desde un siglo XIX con sus atrasos y miedos ya se exigía al mundo científico ser más humano, al sistema colombiano ser menos miserable con los saberes en progreso y con la necesidad de comprender que la ciencia es hecha por humanos y en ese caso es tan importante lo medible como lo sensible.

\section{Bibliografía}

Aguado, Fray Pedro (1954). Recopilación Historial. Notas de Juan Friede, Biblioteca Cultural, Bogotá, 1954.

Alcedo, Antonio de (1967). Diccionario Geográfico Histórico de las Indias Occidentales o América, tomo I, Biblioteca de Autores Españoles, Ediciones Atlas, Madrid.

Ancizar, Manuel (1970). Peregrinación de Alpha, tomo I, Biblioteca Banco Popular, Bogotá.

Arias de Greiff, J. (1967). Una carta de Caldas a Humboldt, Archivos, Academia Colombiana de Historia, (I), 310-325. También en Boletín de la Sociedad Geográfica de Colombia, 26 (99), 141-146.

(1968). Itinerario de Humboldt y Bonpland. Boletín de la Sociedad Geográfica de Colombia, 26 (100), 253-258. 
- (2001). Caldes y Humoldt, transferencia de saberes y prácticas. Revista Credencial, (134), 9, Colombia.

Barrera, S. Monroy J. (Ed.) (2014). Perspectivas ambientales sobre el paisaje, Universidad Nacional de Colombia, Bogotá.

Berque, Augustin (2009). El pensamiento paisajero, Biblioteca Nueva, Madrid.

Berque, A. (2014). El nacimiento del paisaje en China. En L. S., Barrera y H. J., Monroy, Perspectivas sobre el Paisaje, (119-132) Bogotá, Universidad Nacional de Colombia.

Berque, A. (1990). Médiance de milieux en paysages, Montpellier, GEP-Reclus.

Braudel, Fernand (1989). El Mediterráneo, México, FCE.

Caballero, Calderón Eduardo (1956). Suramérica tierra del hombre, Ediciones Guadarrama, Madrid.

Caicedo, Rojas José (1950). Recuerdos y apuntamientos, Biblioteca Popular de Cultura Colombiana, Bogotá.

Caldas, Francisco José de (1942). Semanario del Nuevo Reino de Granada Tomo II, Biblioteca Popular de Cultura Colombiana, Editorial Kelly, Bogotá.

Chartier, Roger (2008). Escuchar a los muertos con los ojos, Katz, Madrid.

Cochrane, Charles Stuart (1994). Viajes por Colombia 1823 y 1824, Colcultura, Banco de la República, Bogotá.

Cortes, Rincón y Sarmiento (1998). Un recorrido a través del paisaje. Revista Cuadernos de Geografía, 7 (1-2), 165 -215.

Cosgrove, D. (2008). Introduction to social formation and symbolic landscape. En Ziady R. and Elkins, J. (Eds.), Landscape Theory, New York, Routledge.

Fernández, de Piedrahita Lucas (1986). Historia general de las conquistas del Nuevo Reino de Granada, Edición facsimilar, Carvajal, Bogotá.

Giraldo, J. (2019). Imaginibilidad urbana y significación cultural en Tunja. Revista Entorno Geográfico, (17), 68-87.

Giraldo, Jaramillo Gabriel (1954). Relaciones de mando de los virreyes de la Nueva Granada. morias económicas, Banco de la República, Bogotá, 1954.

Hernández de Alba, Guillermo (1975). Archivo Epistolar del sabio naturalista Don José Celestino Mutis, tomo III. Cartas al Sabio Mutis letras A-G, Instituto Colombiano de Cultura Hispánica, Bogotá, Editorial Kelly.

Hernández de Alba, Guillermo (1968). Prólogo. Mutis, José Celestino. Archivo Epistolar, vol. III, tomo I, Instituto Colombiano de Cultura Hispánica, Editorial Kelly, I-XXV, Bogotá.

Hernández, Rodríguez, Guillermo (1949). De los Chibchas a la colonia y a la república, Universidad Nacional de Colombia, Bogotá.

Lacarrieré (1973). Herodoto y el descubrimiento de la tierra, Espasa-Calpe, Madrid.

Lacoste, Yves (1976). La geografía un arma para la guerra, Anagrama, Barcelona.

Lemaitre, Eduardo (1998). Historias detrás de la historia de Colombia. Tomo I, Editorial Planeta, Bogotá.

Lynch, Kevin ([1964] 2008). La imagen de la Ciudad, Gustavo Gili, Barcelona.

Maderuelo, J. (2006). El paisaje. Génesis de un concepto, Madrid, Ababa Editores.

Molano, J. (1995). Arqueología del Paisaje. Revista Cuadernos de Geografía, 5 (2), 1-10.

Nieto, C. L. (1984). Escritos escogidos. Tomo V, Amor a Colombia, Bogotá, Biblioteca del Banco Popular. 
Nogue, J. (2010). El retorno al paisaje. Revista Enrahonar, (45), 123-136.

Orozco y Salcedo (2011). El concepto de paisaje y la visión de las comunidades indígenas del nordeste amazónico. Revista Entorno Geográfico, (7-8), 102-123.

Peña, Gómez y Riveros (1998). Esbozo de las discusiones acerca del paisaje. Revista Cuadernos de Geografía, 7(1-2), 216-250.

Piedrahita, P. Jorge Luis (1997). La fuerza de la Patria, Ediciones Jurídicas Gustavo Ibáñez, Bogotá.

Restrepo, Olga, (1999). Un imaginario de la Nación. Lectura de láminas y descripciones de la Comisión Corográfica, Anuario Colombiano de historia social y de la cultura, (26), Universidad Nacional de Colombia, Bogotá.

Rodríguez, Freile Juan (1997). El Carnero. Según el otro manuscrito de yerbabuena, Instituto Caro y Cuervo, Imprenta Patriótica, Santafé de Bogotá.

Rozo, J. D. (2010). Entre la materialidad y la representación: reflexiones sobre el concepto de paisaje en geografía histórica. Revista Cuadernos de Geografía, (19), 77-86.

Samper, José María (1957). Ensayo aproximado sobre la jeografía política i estadística de los ocho estados que compondrán el 15 de septiembre de 1857 la Federación Neo-granadina. Bogotá, Imprenta del Neogranadino.

Santos, Milton (1990). Por una Geografía Nueva, Madrid, Espasa.

- (1996). Metamorfosis del espacio habitado, Editorial Oikos Tau, Barcelona.

Sauer, Carl O. (2006). La morfología del paisaje. POLIS, Revista Latinoamericana, 5(15). https://www.redalyc.org/articulo.oa?id=305/30517306019.

Schumacher, Hermann (1988). Codazzi, un forjador de la cultura, Bogotá, Empresa Colombiana de Petróleos ECOPETROL.

Simón, Fray Pedro (1981) Noticias historiales de las conquistas de Tierra Firme en las Indias occidentales. Notas de Juan Friede Tomo III, Biblioteca Banco Popular, Bogotá.

Tuan, Y. (2009). Geografías Románticas. En busca del paisaje sublime, Madrid, Biblioteca Nueva.

Uribe, White Enrique (Comp.) (1981). El Tequendama: Una recopilación de escritos sobre la Catarata, Bogotana de impresos, Bogotá.

Villegas, Editores (1994). La ruta de Humboldt, Colombia y Venezuela, tomo II, Santafé de Bogotá.

Wallerstein, I. (1996). Abrir las Ciencias Sociales, Siglo XXI, México. 